\section{An investigation into senior high school (shs3) physics students understanding of data processing of length and time of scientific measurement in the Volta region of Ghana}

\author{
Kumassah, Kosi Eliot $\bowtie$ \\ Jasikan College of Education, Ghana (ekumassah@yahoo.com) \\ Ampiah, Joseph Ghartey \\ University of Cape Coast, Ghana (igampiah@ucc.edu.gh)
}

Adjei, Eugene Johnson

University of Cape Coast, Ghana (eugenenajohnson@yahoo.com)

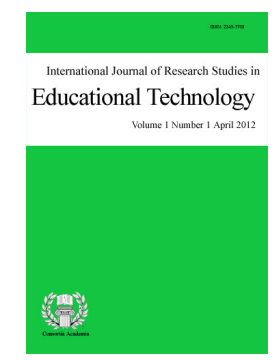

ISSN: $2243-7738$ Online ISSN: 2243-7746

OPEN ACCESS

\title{
Abstract
}

Serious doubt have been raised in the Physics Chief Examiner's report of the West African Examination Council of Ghana of both physics-1 (theory) and physics-2 (practical) as to whether science students really understand measurement of physical quantities. In view of this, the researcher use a mixed designed method to gather data from SHS3 physics students' on their understanding of data processing of length and time. A population of 422 SHS3 physics students were sampled and a three item questionnaire on distance and time administered in order to find out whether the problem enumerated by the Chief Examiners' of Physics concerning physics students exist and were either with the set paradigm or the point paradigm concept. Also twenty SHS3 physics were purposively selected and interviewed in order to validate students' written responses. The study revealed that students do not have an understanding of using repeat in data set, anomaly in data set and straight line graph of data by the set paradigm concept i.e. all the three items on data processing of students (i.e. UR, AN, and SLG) were in line with the point paradigm concept of measurement. Also students seemed to have difficulty in plotting straight line graph by the use of lines of best fit.

Keywords: point paradigm; set paradigm; mixed paradigm; internalized set paradigm; consistent set paradigm 


\section{An investigation into senior high school (shs3) physics students understanding of data processing of length and time of scientific measurement in the Volta region of Ghana}

\section{Introduction}

Science may be seen as a product, a process and an enterprise (Wordsworth, 1998). It is a product because many body of knowledge (i.e. chemistry, physics, mathematics, biology among others) converge to form it (Cardamone, 2007). A process because it involves the use of scientific methodology in exploring and conducting experiments, as well as inquiry (Wordsworth, 1998) and enterprise because it can meaningfully be pursuit in academic and research institutions in order to unearth hidden knowledge (Wordsworth, 1998). Thus science, be it modern or contemporary has advanced, and has reshaped itself by investigating new questions, developing new experimental paradigms, and offering new interpretations. One of the most exciting challenges for today's science is that it investigates individual human experience through knowledge and understanding of concepts such as measurement of physical quantities (Azari \& Bataille, 2003).

Five fundamental or base quantities are in science and all other quantities are related from these fundamental quantities. These fundamental quantities are length (1), time (t), mass (m), electric charge (q), amount of substance (n), temperature $(\mathrm{T})$ and luminescent intensity (cd) are just five examples of the seven fundamental quantities (Bassarath \& Whiteley, 2009).

Physical quantity is a topic in the elective physics syllabus in all categories of senior high schools (Ghana Education Service, 2009) two (SHS2) in Ghana and science students are to show an appreciable understanding of its measurement (Ministry of Education, 2007). Scientists and engineers routinely use physical quantities to represent the measured properties of physical objects. Some mathematicians have studied physical quantities from a more abstract standpoint, with the aim of better understanding the nature and use of those quantities (Sharlow, 2009).

Experimentation and measurement are fundamental to knowledge production in both the applied and natural sciences, including technology. Meaningful engagement by students in scientific activities that are experimentally based requires an understanding of science concepts for the procedures that are followed (Allie, Buffler, Campbell, \& Lubben, 2001). However, most science students in senior high schools in Ghana find difficulty in understanding measurement of physical quantities and processing of experimental data, the physics Chief Examiner's report of the West African Examination Council (WAEC, 2000, 2002, \& 2006). Other countries such as USA, Australia, Denmark, Sweden and South Africa (Allie, Buffler, Campbell, \& Lubben, 2003; Deardorff, 2001; Lippmann, 2003) also faced similar problems with their science students as has already been indicated by the physics Chief Examiner's report of the West African Examination Council (WAEC, 2000, 2002, \& 2006). Due to this, the researcher deems it right to carry out an investigation into physics students' understanding of data processing of length and time in category A, category B, category C, and category D senior high schools in the Volta region of Ghana (Ghana Education Service, 2009).

\subsection{Statement of the Problem}

Although practical work forms part of the senior high school physics curricula in Ghana (Ministry of Education, 2007), it is not clear as to the level at which senior high school physics students in category A, category B, category C, and category D senior high schools in the Volta region of Ghana understand the basic ideas of measurement of physical quantities and the appropriateness of the data treatment procedures that they learn to use (WAEC, 2000, 2002 and 2006). All what is usually expected is that after the senior high school physics laboratory course, physics students should able to use an array of data analysis techniques, such as calculating the mean, standard deviation of the mean of physical quantities (Ministry of Education, 2007) but not 
the understanding of the concepts of measurement (Anamuah-Mensah, Mensah, \& Otuka, 2001).

Also serious doubt have been raised in the Physics Chief Examiner's report of the West African Examination Council of Ghana (WAEC, 2000, 2002, \& 2006) of both physics-1 (theory) and physics-2 (practical) as to whether science students really understand data processing of physical quantities. For example the November / December, 2000 Chief Examiner's report of Physics indicated that many science candidates made deductions after obtaining only one reading from their experiments.

The one deduction made by the science students after obtaining one result from their practical examination, that is physics-2 (practical) examination as reported by the Physics Chief Examiner's report of the West African Examination Council of Ghana (WAEC, 2000, 2002 and 2006) was in line with the point paradigm concept of measurement i.e. the point paradigm concept is characterized by the underlying notion that each measurement could in principle be the true value (Allie, Buffler, Campbell, \& Lubben, 2003).

However, while the Physics Syllabus of Ghana for senior high schools and some researches in pure sciences, applied science and science education strongly subscribed to the use of the set paradigm concept (i.e. all available data are used to construct distributions from which the best approximation of the scientist and an interval of uncertainty are derived) by science students and scientist the world over (Allie, Buffler, Campbell, \& Lubben, 2003; Bassarath \& Whiteley, 2009; Ministry of Education, 2007; Wilson, 2009) when it comes to measurement of physical quantity, yet many science students in Ghana still made deductions after taken one measurement (WAEC, 2000).

The July/August, 2002 and 2006 Physics Chief Examiner's reports revealed further that, many science candidates did not repeat experimental readings so that two sets of values could be obtained and a mean taken. This implies that the Physics Chief Examiner's reports of 2002 and 2006 expected science students to repeat their experimental readings so that two or more sets of data can be obtained for the calculation of mean (average). This assertion is in line with the set paradigm concept of measurement of physical quantities where by experiments are to be repeated to get means, standard deviation of the mean and variance of the mean (Allie, Buffler, Campbell, \& Lubben, 2001) in order to reduce or minimize random errors or any other errors aside random errors in measurement of physical quantities. This is because, one experiment cannot give the true value', unless that experiment is performed several times, and the mean of the numerous data collected is estimated to eliminate uncertainties in measured results (Wilson, 2009; Bassarath \& Whiteley, 2009).

These lapses enumerated by the Physics Chief Examiner's report of the West African Examination Council of Ghana (WAEC, 2000, 2002 and 2006) of both physics-1 (theory) and physics-2 (practical) could either be due to anxiety of physics students during the examination or the type of examination questions set by the West Africa Examination Council or the lack of understanding of measurement of physical quantities or the holding onto either the set paradigm concept or the point paradigm concept or the mixed paradigm by some science students or the students own conception. It is therefore worthwhile to investigate into physics students understanding of data processing of length and time in SHS3 in category A, category B, category C, and category D senior high schools in the Volta region in order to understand the causes of these confusion and misunderstanding by science students so that instruction on this subject can be improved.

\subsection{Purpose of the Study}

The purpose of this study is to; explore SHS3 physics students' understanding of data processing of length and time in category A, category B, category $C$, and category D senior high schools in the Volta region.

\subsection{Significance of the Study}

The findings of the study would be significant in the following ways:

It could help provide some guide to physics teachers and students in order to assist and improve students' 
skills in practical activities involving data processing of length, and time. It could provide information to physics teachers on students' difficulties in data processing of length, and time, so that teachers would find appropriate method of approaching the data processing concept. It could also provide information to the Ministry of Education, policy makers and the general public on students' difficulties in data processing of length and time, so that the Ministry of Education, policy makers and the general public would design appropriate educational policies of approaching the data processing.

\subsection{Research Question}

What is SHS3 physics students' understanding of data processing of length and time in category A, category $\mathrm{B}$, category $\mathrm{C}$, and category $\mathrm{D}$ senior high schools in the Volta region?

\subsection{Delimitation}

This study used only SHS3 physics students in data processing; this was because, by the time the physics students from SHS2 get to SHS3 in their various schools, they might have been taught measurement of physical quantities as has been specified in the physics syllabus, 2007. Thus, SHS3 physics students would be in the best position to respond meaningfully to the closed and opened ended questionnaire items and structured interview items of the study.

This study also considered only length and time aspect of measurement of physical quantities. This was because, these two physical quantities i.e. length and time, are fundamental quantities and also it form daily measurements that students undertake either in their schools or homes.

This study also considered only the understanding of SHS3 physics students in data processing of measurement of length and time.

\subsection{Limitation}

Some of the students were absent on the agreed day for the administration of the closed and opened ended questionnaire item in the rest of the selected category of schools.

\section{Review of Related Literature}

\subsection{Data Processing}

Data processing deals with handling, analysis and interpreting of data (Sinex, 2005). To be able to process a data, some processes/methods has to be undertaken such as sketching a graph of the given data, usually a scatter plot; looking for trends in the given data, describe the trends in the given data in a qualitative fashion; finding out if there is a mathematical relationship to describe the trend; and seek answers to question such as "Does the trend really mean something?" For example, Looking at the six (6) x-y plots/ graph below describes the behaviour of the variables $\mathrm{x}$ and $\mathrm{y}$; and also tries to establish a trend between the data of the $\mathrm{x}$ and $\mathrm{y}$ variables (Sinex, 2005).

\subsection{Empirical Studies on Students' Understanding of Data Processing}

In 2001, the procedural understandings of first year university students before and after instruction were investigated in the context of experimental work in physics by (Allie, Buffler, Campbell, \& Lubben, 2001). A written instrument was used to probe the students' ideas about data collection, data processing and data comparison. The responses of the students were analyzed in terms of "point" and "set" paradigms which were proposed as a framework for evaluating the effectiveness of laboratory curricula in South Africa. 
Since most of the South African First year Physics students had little or no first hand practical experience, a prime aim of the laboratory course was to develop the notion of measurement. Aspect of data processing was addressed by exercises such as drawing up tables, taking several measurements of a quantity, plotting graphs, fitting straight lines, and calculating the mean and the standard deviation from the statistical formulae as well as graphically from a Gaussian curve. The idea of spread in data was introduced by getting the class to measure the time of travel of a sound pulse over a given distance. The readings were processed to form a distribution (a Gaussian curve results) from which the key ideas of mean and uncertainty were introduced.

A
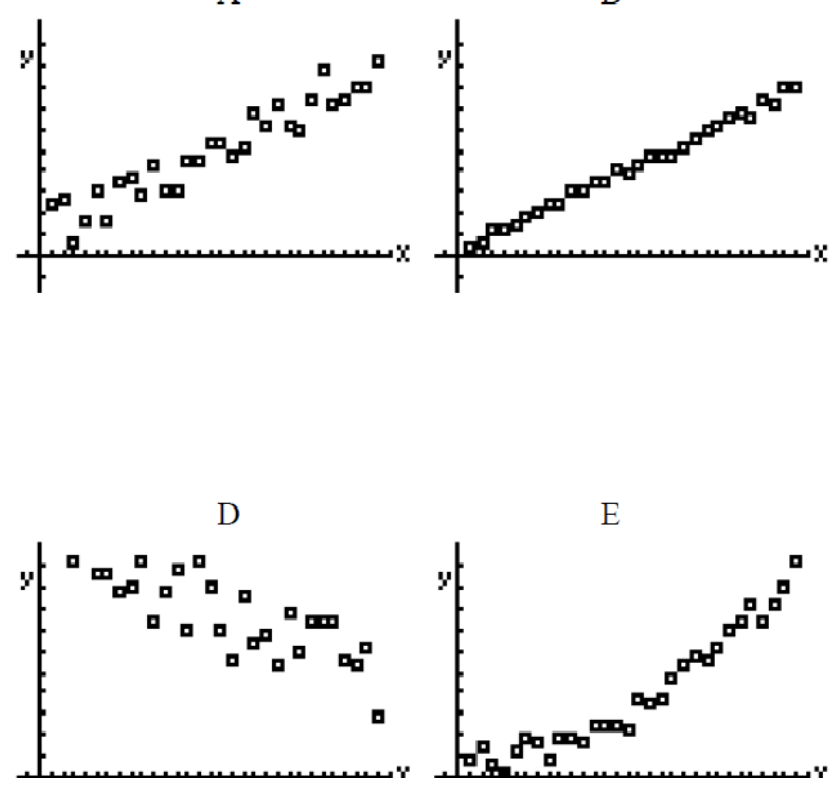

B
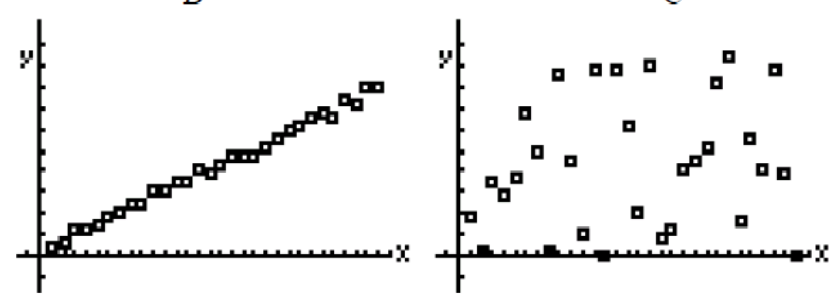

Figure 1. The Six (6) X-Y plots/ graph

One of the data processing probes required a mean to be calculated from a set of numerical data, while the other required a straight line to be drawn to a set of graphical data. It is interesting to note that there appeared to be a strong link between the paradigms used for these two probes. For example, students who joined individual data points (i.e. did not fit a straight line to the data as a whole) often evidenced point paradigm concept use in the other probe by choosing the recurring value to represent the data rather than calculating a mean. Only about a fifth $(21 \%)$ of the students based their responses on the set paradigm concept for all of data collection, data processing and data-set comparison and that the largest group (37\%) was inconsistent in their use of the paradigms. Thus it was clear that although more than half the students (57\%) carried out an action associated with the set paradigm concept; fewer than half of this group (23\% of the sample) provided a reason that was also consistent with this paradigm. In other words $33 \%$ of the students appear to have used the correct set paradigm concept action either by rote or in an ad hoc way. In summary, only a quarter of all the students can be regarded as having completely embraced the set paradigm concept.

Teaching activities are required which allow students to appreciate the collective nature of a series of measurements and that the mean and the width represent the set of measurements as a whole. A student's intuition regarding the spread in data needs to be explicitly linked to the formal mathematical procedures for analyzing the spread in data set. A similar conclusion has also been reached by Evangelinos, Psillos, and Valassiades (2002) who recommended that 'probabilistic reasoning in the context of lab work should be presented not only as a technique for data treatment but as an inherent feature of scientific enquiry'. In particular, they attempted to devise a teaching sequence that utilised the students' everyday notion of 'approximate' in bridging the gap between 'exact' (point paradigm concept) and 'probabilistic' (set paradigm concept) types of reasoning. 


\subsection{Research Design}

The design of this study was a mixed method research design. It is a combination of qualitative and quantitative techniques (Ary, Jacobs, \& Razavieh, 2002). The quantitative technique was used to test the research question of the study on SHS3 physics students' understanding of data collection, of length and time. Cross-sectional survey (Ary, Jacobs, \& Razavieh, 2002) was used in this study with SHS3 physics students. The SHS3 physics students were randomly selected from category A, category B, category C, and category D (Ghana Education Service, 2009) schools in Volta region. The close and opened ended questionnaire items was adapted from Allie, Buffler, Campbell, and Lubben (2003) and used to gather data from SHS3 physics students on their understanding of data processing of length and time.

All the intact class of SHS3 physics students in each of the categories of schools were involved in the study. The close and opened ended questionnaire items were based on SHS3 physics students understanding of data processing of length and time. The use of the adapted close and opened ended questionnaire items (Allie, Buffler, Campbell, \& Lubben, 2003) from Department of Physics of the University of Cape Town, South Africa and University of York, UK was appropriate in this study because it helped the researcher in this study.

In addition to the close and opened ended questionnaire items of the cross sectional survey design, structured interview of the SHS3 physics students was also conducted to elicit further information from physics students which might not have appeared on the questionnaire items and to also validate the written responses of the students on the questionnaire items.

\subsection{Population}

The population of the study was 642 SHS3 science students in Volta region. These SHS3 science students were selected from eleven (11) SHS and one (1) SHTS in Volta region (Ghana Education Service, 2009). The twelve SHS and SHTS were categories into category A, category B, category C and category D (Ghana Education Service, 2009).

\section{Sample and Sampling Procedure}

The sample for the study was 422 SHS3 and SHTS3 science students. This sample size of science students were simple randomly selected from the population. Within this 422 science students, 20 students were again sampled purposively and interviewed. The 20 students were purposively selected based on how they responded to the questionnaire items of the study. The 422 sample size of SHS3 and SHTS3 science students formed $65.73 \%$ of the 642 of SHS3 and SHTS3 of science students in the eleven SHS and one SHTS in the region. The $65.73 \%$ sample of the population in this study was more than $10 \%$ sample of the population as indicated in (Ary, Jacobs, \& Razavieh, 2002); they argued that for a descriptive research, it is convenient to select 10 to 20 percent of the population. A sample of $65.73 \%$ of the population was therefore appreciably adequate for this study.

Simple random sampling method was used to select the sample for the study. This was done in order to get an appreciable representation of students in each category of schools i.e. category A, category B, category C and category D (Ghana Education Service, 2009). A total of four hundred and twenty two (422) SHS3 and SHTS3 physics students were sampled for the study. These total numbers of four hundred and twenty two (422) SHS3 and SHTS3 physics students were made up as follows;

$>\quad$ The first SHS was a category A school. It had Forty nine (49) students present in class at the time of administration of the test.

$>\quad$ The second SHS was a category A school. It had Forty nine (49) students present in class at the time of administration of the test.

$>\quad$ The third SHS was a category B school. It had forty six (46) students present in class at the time of 
administration of the test.

$>\quad$ The four SHS was also a category B school. It had thirty seven (37) students present in class at the time of administration of the test.

$>\quad$ The five SHS was also a category B school. It had thirty nine (39) students present in class at the time of administration of the test.

$>\quad$ The sixth SHS was a category C school. It had thirty eight (38) students present in class at the time of administration of the test.

$>\quad$ The seventh SHS was a category D school. It had forty (40) students present in class at the time of administration of the test.

$>\quad$ The eighth SHS was also a category C school. It had twenty three (23) students present in class at the time of administration of the test.

$>\quad$ The ninth SHS was also a category A school. It had thirty six (39) students present in class at the time of administration of the test.

$>\quad$ The tenth SHS was also a category D school. It had thirty eight (38) students present in class at the time of administration of the test.

$>\quad$ The eleventh SHS was also a category D school. It had thirty seven (37) students present in class at the time of administration of the test.

$>\quad$ The twelfth SHS was also a category C school. It had twenty six (23) students present in class at the time of administration of the test.

Eleven SHS and one SHTS offering physics in the various categories of schools by the Ghana Education standard were randomly selected from the thirty 32 SHS and SHTS (Ghana Education Service, 2009). All the twelve SHS and SHTS were selected from the categories based on classification of Ghana Education Service, which is Category A, Category B, Category C and Category D (Ghana Education Service, 2009). The selections of the eleven SHS and one SHTS were done by using Microsoft Excel software. A list of names of category A, category B, category C, and category D were obtained (Ghana Education Service, 2009). These names of schools in their categories were imputed into Microsoft Excel software. All the schools in the categories were highlighted, and then sort ascending in the tool bar of Microsoft Excel software clicked. This was done to arrange the schools in each category in alphabetical order. Rand also in the tool bar of the auto sum of Microsoft Excel software was clicked to assign random numbers to each of the schools in each category. Since this study looks at physics students understanding of measurement of length and time, but not physics students' performance in senior high schools, the use of the classification of Ghana Education Service is appropriate for this study. The reason being that the classification (Ghana Education Service, 2009) was based on the availability of facilities (i.e. boarding or day, and classrooms among other facilities) in the senior high schools of Ghana, but not on performance of students and students' entry behaviors.

With this $65.73 \%$, three SHS or SHTS were selected from the category A schools, three SHS or SHTS from the category B schools, three SHS or SHTS from the category C schools and three SHS or SHTS from the category D schools. The reason for these $65.73 \%$ selection of physics students from each category of schools was based on the assumption that the sample size of a population should not be less than 10\% (Ary, Jacobs, \& Razavieh, 2002). Thus selecting $65.73 \%$ sample size from each category would give a fair representation of SHS3 or SHTS3 of physics students to be included in the study. Each selected school was identified by a confidential code alphabet. Also each student in the selected school was identified by their names thereafter and throughout the study. Students' names were used in the study in order to identify them for interviewing. Table 1, 
Kumassah, K. E., Ampiah, J. G., \& Adjei, E.

shows the coding of both senior high schools with the size of the participated SHS3 and SHTS3 physics students in each of the school.

\section{Table 1}

Alphabet Codes of Senior High Schools and Number of participated SHS3 Physics Students

Category A Schools

\begin{tabular}{lll}
\hline School Code & Students Codes & $\begin{array}{l}\text { Number of participated SHS3 } \\
\text { physics students }\end{array}$ \\
\hline $\mathrm{A}_{1}$ & $\mathrm{~A}_{1(1)}-\mathrm{A}_{1(50)}$ & 49 \\
$\mathrm{~A}_{2}$ & $\mathrm{~A}_{2(1)}-\mathrm{A}_{2(50)}$ & 49 \\
Total & & 98 \\
\hline
\end{tabular}

\begin{tabular}{lll} 
Category B Schools & & \\
\hline School Code & Students Codes & $\begin{array}{l}\text { Number of participated SHS3 } \\
\text { physics students }\end{array}$ \\
\hline $\mathrm{B}_{1}$ & $\mathrm{~B}_{1(1)}-\mathrm{B}_{1(50)}$ & 46 \\
$\mathrm{~B}_{2}$ & $\mathrm{~B}_{2(1)}-\mathrm{B}_{2(50)}$ & 37 \\
$\mathrm{~B}_{3}$ & $\mathrm{~B}_{3(1)}-\mathrm{B}_{3(50)}$ & 39 \\
Total & & 122 \\
\hline
\end{tabular}

Category C Schools

\begin{tabular}{lll}
\hline School Code & Students Codes & $\begin{array}{l}\text { Number of participated SHS3 } \\
\text { physics students }\end{array}$ \\
\hline $\mathrm{C}_{1}$ & $\mathrm{C}_{1(1)}-\mathrm{C}_{1(50)}$ & 38 \\
$\mathrm{C}_{2}$ & $\mathrm{C}_{2(1)}-\mathrm{C}_{2(50)}$ & 23 \\
$\mathrm{C}_{3}$ & $\mathrm{C}_{3(1)}-\mathrm{C}_{3(50)}$ & 26 \\
Total & & 87 \\
\hline
\end{tabular}

Category D Schools

\begin{tabular}{lll}
\hline School Code & Students Codes & $\begin{array}{l}\text { Number of participated SHS3 } \\
\text { physics students }\end{array}$ \\
\hline $\mathrm{D}_{1}$ & $\mathrm{D}_{1(1)}-\mathrm{D}_{1(50)}$ & 40 \\
$\mathrm{D}_{2}$ & $\mathrm{D}_{2(1)}-\mathrm{D}_{2(50)}$ & 38 \\
$\mathrm{D}_{3}$ & $\mathrm{D}_{3(1)}-\mathrm{D}_{3(50)}$ & 37 \\
Total & & 117 \\
\hline
\end{tabular}

\subsection{Instruments}

The research instrument (close and opened ended questionnaire) was adapted from (Allie \& Buffler, Campbell, \& Lubben, 2003) for the study. This was accompanied with a structured interview for respondents to give opinions on each item in the close and opened ended questionnaire items. The close and opened ended questionnaire items was adapted (Allie, Buffler, Campbell, \& Lubben, 2003) for this study because it was the most appropriate instrument in view of the purpose of the study considering the financial and time constraint of the study.

The close and opened ended questionnaire items were of one dimension i.e. SHS3 physics students understanding of data processing of length and time. It was comprised of three close ended or multiple-choice items and its corresponding three easy or opened ended items (Using Repeat, Anomaly in data set and Straight Line Graph). The corresponding easy or opened ended items of the close ended or multiple-choice items was for 
Nature of classroom environment and achievement in integrated Science

the SHS3 physics students to illuminate their reasoning of each of the option selected in the close ended or multiple-choice items. Each of the items in the questionnaire under the dimension was targeted at a particular aspect of measurement and seeks to determine students' decision and at the same time illuminated students reasoning.

The dimension has been put into three questionnaire items. All the items under the dimension in the questionnaire had the same form. A brief stem of text posited a situation where decisions had to be made concerning the experimental procedure (Appendix A). A number of options were presented in each item of the questionnaire by cartoon characters, purposely included to avoid gender and race bias in influencing the respondent's choices. The questionnaire items called for an explanation of each choice made by the physics students in each item.

The questionnaire item was in two parts i.e. part one and two. Part one consisted of five items. These four items elicited information on physics students' background, which were students surname, students' first name, location and type of school. This student's background was used to help identify each student for interviewing. Part two consisted of the dimension, which were students understanding of data processing, (Appendix A).

The close and opened ended questionnaire item was of duration of sixty five minutes. Five minutes was allowed for the students to read through the given questionnaire items and for any further questions and further clarification before the commencement of the questionnaire items. Sixty minutes for the actual answering of the given close and opened ended questionnaire items by the students. The sixty minute time was allowed in order that the students would have ample time to respond to the close and opened ended questionnaire items, since the questionnaire items was not a speed test but rather an understanding of measurement of distance and time, thus the questionnaire items requires much time for the students to respond since it involves much reasoning and thinking by the students.

\subsection{The Interview Guide}

A variety of interview methods exist (Ary, Jacobs, \& Razavieh, 2002), they are standardized (structured), semi-standardized (semi-structured), and un-standardized (unstructured). The decision to use the structured interview as a follow up data gathering method to the questionnaire item was influenced by (Ary, Jacobs, \& Razavieh, 2002). They maintained that structured interview allows respondents to freely speak for themselves in order to provide their perspective in words and other actions, and that it usually involves personal visit to respondents at home, at school and at work.

In this study, the interview guide schedule was made up of three items (i.e. UR, AN, and SLG) see Appendix B. The three interview schedule items were comprised of five questions each. Two questions went for students who had the questionnaire items wrong, and three questions went for students who had the questionnaire items right. Even though structured interview usually involves much cost on the part of the researcher such as it took a great deal in meeting the students, interviewer bias which is due to the interviewer own feelings, attitudes, gender, race age and among others which might influence the way and manner the questions were asked, and social desirability which occurs when respondents want to please the interviewer by giving acceptable responses that might not have necessarily be given on the questionnaire items and also time consuming when it comes to the transcribing of the interview responses (Ary, Jacobs, \& Razavieh, 2002). However, its use in this study allowed the researcher enough flexibility in re-wording questions that would fit into the interview, it was more conversational, and it made the interviewee saw, and felt the need to be interviewed on items in the questionnaire (Ary, Jacobs, \& Razavieh, 2002).

Also it enabled the researcher find the target sample to be interviewed and most importantly it served as a backup instrument to the close and opened ended questionnaire items. This back up instrument enabled the researcher to cross examine the physics students who had earlier responded to the close and opened ended questionnaire items (Ary, Jacobs, \& Razavieh, 2002). The cross examination enable the researcher to verify 
whether the students responses to items in the close and opened ended questionnaire were really what they meant or otherwise or whether the written responses of the physics students were interpreted in line with the ideas the physics students wanted to communicate (Ary, Jacobs, \& Razavieh, 2002).

The responses from the students involved in the interview were hand written by the researcher. Audio taping might have been better but because audio taping of responses from respondents may possibly make the students nervous, less apt to listen and less apt to respond freely because students responses would be recorded (Ary, Jacobs, \& Razavieh, 2002) it was better for the researcher to write their responses down with the use of pen and paper. The structured questions were focused on SHS3 physics students understanding of data collection of length and time in category A, category B, category C, category D schools in Volta region.

\subsection{Validity Reliability of the Instrument}

The instrument of the study had already been validated with 230 South African freshmen undergraduate students (Allie, Buffler, Campbell, \& Lubben, 2003). Allie, Buffler, Campbell and Lubben (2003) developed a range of items on a questionnaire for use in their investigation. Each of the items in the questionnaire was targeted at a particular aspect of measurement and sought to determine students' decision and at the same time illuminated students reasoning. This questionnaire was validated by giving it to other research members to independently look at. This was done in order to identify different categories of reasoning. They further went ahead to interview thirty (30) volunteered students for about thirty (30) minutes. The interview allowed (Allie, Buffler, Campbell, \& Lubben, 2003) to further validate the close and opened ended questionnaire items by checking on students understanding of the questionnaire items and the interviewers' interpretation of their responses.

However, since the same instrument was used in this study with Ghanaian SHS3 physics students, face and content validity were again assessed by given the questionnaire item to three SHS physics teachers from the pre testing school (University Practice Senior High School) in Cape Coast, and two colleagues who majored in physics. They were given the close and opened ended questionnaire items and were asked to assess the quality of each item of the questionnaire. This was done in the context of ambiguity of item, clarity of item and generality of item. The three physics teachers and the two colleagues of physics worked independently on evaluation of the close and opened ended questionnaire items. They independently approved on the questionnaire items adapted from Allie, Buffler, Campbell and Lubben (2003). This meant that all the items of the questionnaire were clear, not ambiguous and every SHS3 physics students in Ghana can respond to it. However, the reliability of the research instrument was ignored, since the internal consistence value (i.e. crombach alpha) was too small i.e. 2.6, so the researcher rather concentrated on triangulation of research instrument i.e. validity of the research instrument, since validity is the most important aspect of testing a research instrument (Ary, Jacobs, \& Razavieh, 2002).

The validity of the instrument was improved by conducting a pretest using an intact class of SHS3 physics student of in University Practice Senior High school (UPSS) in the Cape Coast municipality. The questionnaire item was distributed personally by the researcher to the SH3 physics students in their science classroom. The SHS3 physics students responded to the questionnaire items in the presence of the researcher. The questionnaire items were collected after completion, personally by the researcher and then analyzed. The intact class was made up of forty six (44) SHS3 physics students. The mean of the intact class was 32.00; the standard deviation was 24.83; and variance 616.56. The pre-tested school was randomly selected from six (6) schools. The pretest was done so that the ambiguous items in the questionnaire could be removed or reworded so that they would have the same meaning for the respondents. The validity of the instrument was further enhanced by conducting personal interview with twenty SHS3 physics students purposively selected by the researcher. The twenty physics students were purposively selected because of the way they responded to the questionnaire items. The twenty physics students that were involved in the interview were spread into the four categories of schools i.e. category A, category B, category C and category D. This means that five physics students were interview from each of the 
categories of schools.

\subsection{Data Collection Procedure}

Before the research data were collected from SHS3 physics students, an introduction letter was first taken from the head, Department of Science and Mathematics Education of University of Cape Coast and sent to the selected categories of schools. Initial visits were made to the selected categories of schools in order to meet the heads, deliver the research visit introductory letter from the Department of Science Education and to familiarize with the SHS3 physics students and the subject tutors. The meeting of the heads of schools, teachers and students enabled the researcher an opportunity to explain the objectives of the study and to seek their consent to conduct the research in their schools. It also helped the researcher the opportunity to agree on the day(s) and time for the administration of the research instruments. It also gave the schools and SHS physics students the opportunity to decide on when to respond to the closed and opened ended questionnaire items; whether to respond to the questionnaire items before the normal hours, during the school hours or after the school hours.

On the actual day for the data collection in the schools, the researcher re-explained the rationale of the study to the SHS physics students and assured them of confidentiality of their responses. The researcher with the help of the subject tutors administered the closed and opened ended questionnaire to the SHS3 physics students on the same day. An intact class of SHS3 physics students was used throughout in each of the selected schools. Each of the closed and opened ended questionnaire lasted for sixty minutes. The instrument did not require the use of gender (Allie, Buffler, Campbell, \& Lubben, 2003). It took the researcher duration of two weeks to move round the twelve (12) selected schools to collect data.

\subsection{Data Analysis}

Research question i.e. what is SHS-3 Physics understanding of data processing of length and time in category A, category B, category C, category D schools in Volta region? Was analyzed using frequency distribution by the use of SPSS 16.0 .

The criteria that was employed to determine students understanding of data processing of length and time was $50 \%$ using frequency distribution by the use of SPSS 16.0. Thus below $50 \%$ students understanding was with the point paradigm concept and above 50\% students understanding was with the set paradigm concept. Correct option went for 'set paradigm concept'; wrong option went for point 'paradigm concept', unclear students written response went for 'Not Classified' and a mixer of correct option but wrong written response and vice versa went for 'mixed paradigm state' and any other written response which is not either right or wrong went for 'confusion / own paradigm state . Determination of range of values with calculation of mean went for internalized set paradigm concept. Determination of range of values without the calculation of mean went for consistent set paradigm concept.

\section{Results and Discussions}

\subsection{Students' Understanding of Data Processing}

The research question sought to find out SHS-3 physics students' understanding of data processing. Students' understanding of data processing was tested on three items i.e. using repeat (UR), anomaly in data set (AN) and straight line graph (SLG).

Using Repeat (UR) Item

The UR item sought to find out from students whether they will be able to add all the results and find the average, since the range of the individual data was not too wide. The expected response from students is $d=432$ $\mathrm{mm}$. $\mathrm{d}=432 \mathrm{~mm}$ was correct because of the set paradigm concept specified in the Physics Syllabus for Senior 
Kumassah, K. E., Ampiah, J. G., \& Adjei, E.

High Schools in Ghana.

The percentage number of students that wrote $d=432 \mathrm{~mm}$ was $37.6 \%$. This $\mathrm{d}=432 \mathrm{~mm}$ (Table 2 ) is in line with the set paradigm concept; hence the students seemed not to understand using repeat.

Table 2

Students' selected option on UR $(N=422)$

\begin{tabular}{llll}
\hline Items & Paradigm Type & Frequency & Percent \\
\hline Using Repeat & Point & & \\
& Paradigm concept & 265 & 62.4
\end{tabular}

Set

$\begin{array}{ll}\text { Paradigm concept } \quad 157 & 37.6\end{array}$

Students' written responses were coded 'Not Classified' meaning students' responses were not clear to the researcher; and 'No Explanation' meaning students were not able to give any response or explanation to their selected options.

Students were expected to find the average result by writing $\mathrm{d}=432 \mathrm{~mm}$ as the distance of the ball. The responses of the students to $\mathrm{d}=432 \mathrm{~mm}$ would show whether their reasoning is in line with the reasoning of the set paradigm concept on repeating distance. Thus by the set paradigm concept, the reason for calculating average distance of the ball is to see how far the average result deviates from the individual results and in so doing minimizes experimental errors in the recording of the distance of the ball.

The responses from students on using repeat were expected to be all individual values were added and divided by the number of outcomes to get an average result that becomes an approximate distance for the ball. With this response, the students could be said to have internalise the set paradigm concept. The number of students that could be said to have internalised the set paradigm concept was $56.6 \%$. However, $1.3 \%$ of the students (Table 3) were consistently with the set paradigm concept, while $39.7 \%$ of students were not able to explain the option they selected. The findings of this study on using repeat does agree with Allie, Buffler, Campbell, and Lubben (2003) in the sense that most of the students as at the time were classified as subscribing to the point paradigm concept prior to instruction.

Table 3

Students' written response on Using Repeat (UR)

\begin{tabular}{lll}
\hline UR $(432 \mathrm{~mm})$ written response & Frequency & Percent \\
\hline $\begin{array}{l}\text { No Explanation } \\
\text { Not classified. }\end{array}$ & 89 & 39.7 \\
$\begin{array}{l}\text { Because the test have been performed } \\
\text { for about five times and each distance is noted. }\end{array}$ & 3.7 \\
$\begin{array}{l}\text { Because by adding all the releases of the ball } \\
\text { and divide by } 5 \text { would give the average } \\
\text { distance which then serves as the correct } \\
\text { distance of the ball. }\end{array}$ & 126 & 56.6 \\
\hline
\end{tabular}

\subsection{The Anomaly (AN) Item}

The anomaly in data set item sought to find out from students whether they would be able to identify and 
Nature of classroom environment and achievement in integrated Science

remove an outlier or an extreme value within a given data. The reason for identifying and removing an outlier in a data is that its presence in a data might affect the mean value of the data, and hence might not give the true representation of the data. The expected response required from the students' is option (B); No we should ignore $\mathrm{d}=588 \mathrm{~mm}$ and then add the rest and divide by 5 .

The percentage number of students that selected option (B) was 33.5\%. This selected option (Table 4) is in line with the set paradigm concept; hence the students seemed not to understand anomaly in data set.

\section{Table 4}

Students' selected options on $A N(N=422)$

\begin{tabular}{llll}
\hline Items & Paradigm Type & Frequency & Percent \\
\hline Anomaly & Point & 281 & 66.5 \\
& Paradigm concept & & \\
& Set & 141 & 33.5 \\
& Paradigm concept & & \\
\hline
\end{tabular}

Students' written responses were coded 'No Explanation' meaning students were not able to give any response or explanation to their selected options; and 'Not Classified' meaning students' responses were not clear to the researcher.

Students were expected to ignore $d=588 \mathrm{~mm}$ and then add the rest of the results to determine the average result by writing $\mathrm{d}=432 \mathrm{~mm}$ as the distance of the ball. The responses of the students to $\mathrm{d}=432 \mathrm{~mm}$ would show whether their reasoning is in line with the reasoning of the set paradigm concept on anomaly in data. Thus by the set paradigm concept, the reason for ignoring an extreme value in a data set is to minimize errors in a data set after the experiment has been performed. This is because the extreme value in a data set could be due to error in the instrument and or human errors.

\section{Table 5}

Students' written response on $A N,(N=364)$

\begin{tabular}{|c|c|c|}
\hline AN (B) written response & Frequency & Percent \\
\hline No Explanation & 242 & 66.5 \\
\hline Not classified & 11 & 3.0 \\
\hline $\begin{array}{l}\text { Because } 588 \mathrm{~mm} \text { is out of range by exceeding } \\
\text { all other values, so it should be ignored }\end{array}$ & 78 & 21.4 \\
\hline $\begin{array}{l}\text { Because } 588 \mathrm{~mm} \text { is far away from the } \\
\text { rest of the measurement, whole the } \\
\text { rest of the measurement are closer to each }\end{array}$ & & \\
\hline $\begin{array}{l}\text { other with some small interval within } \\
\text { them. Thus } 588 \mathrm{~mm} \text { should be ignored and } \\
\text { the rest of the measurement added and } \\
\text { divided by } 5 \text { to get the average result. }\end{array}$ & 33 & 14.7 \\
\hline
\end{tabular}

The responses from students on anomaly in data set were expected to be ignoring $\mathrm{d}=588 \mathrm{~mm}$ and the rest of the values added and an average determined to get an approximate distance for the ball. With this response, the students could be said to have internalize the set paradigm concept. The number of students that could be 
Kumassah, K. E., Ampiah, J. G., \& Adjei, E.

said to have internalized the set paradigm concept was $14.7 \%$. However, $21.4 \%$ of the students (Table 5) were not able to include the calculation of mean after ignoring $\mathrm{d}=588 \mathrm{~mm}$, thus these students could be said to consistently be with the set paradigm concept. Also $3.0 \%$ of students were observed to be confused (i.e. not classified) and $66.5 \%$ were not able to explain the option they selected. The findings of this study on anomaly in data set does agree with Allie, Buffler, Campbell, and Lubben (2003) in the sense that most of the students as at the time were classified as subscribing to the point paradigm concept prior to instruction.

\subsection{The Straight Line Graph (SLG)}

The SLG item sought to find out from students whether they will be able to draw a line that will pass through the first plotted point closest to the zero spot on the (distance-time) graph and the last plotted point far away from the zero point, so that two plotted points will be up the straight line and three plotted points will be down the straight line. By this then most of the plotted point will be very close to the straight line than the plotted points being far away from the straight line on the graph in order to prevent overloading of the graph.

The percentage number of students that drew a straight line graph such that the straight line passes through two points, with two points up the line and three points down the line was $16.5 \%$. The drawing of such a graph (Table 6) is in line with the set paradigm concept; hence the students seemed to have difficulty in plotting a straight line graph.

\section{Table 6}

Students' selected options on $S L G(N=422)$

\begin{tabular}{llll}
\hline Items & Paradigm Type & Frequency & Percent \\
\hline Straight Line Graph & Point & 352 & 83.5 \\
& Paradigm & & \\
& concept & & 16.5 \\
& Set & 70 & \\
& Paradigm & & \\
& concept & & \\
& & & \\
&
\end{tabular}

Students' written responses were coded 'Not Classified' meaning students' responses were not clear to the researcher; and 'No Explanation' meaning students were not able to give any response or explanation to their selected options.

Students were expected to plot a straight line graph such that two points will be up the line and three points will be down the line by employing the concept of lines of best fit. The responses of the students to the plotting of such a graph would show whether their reasoning is in line with the reasoning of the set paradigm concept on straight line graph. Thus by the set paradigm concept, the reason for plotting such a graph is to determine whether the difference between the points up the straight line on the graph and down the same straight line is one. The difference between the points must be one in order to prevent overloading of the graph and also to be able to determine the average results that serve as the representative of the other results.

The responses from students on straight line graph were expected to be two points up the line and three points down the line. With this response, the students could be said to have internalize the set paradigm concept. The number of students that could be said to have internalized the set paradigm concept was $4.9 \%$. However, $78.3 \%$ of the students (Table 7) were not able to explain the option they selected. Also 6.7\% of students were observed to be confused (i.e. not classified) and $9.4 \%$ of students were observed to be consistently with the set paradigm concept. The findings of this study straight line graph does agree with Allie, Buffler, Campbell, and Lubben (2003) in the sense that most of the students as at the time were classified as subscribing to the point paradigm concept prior to instruction. 
Table 7

Students' written response on Straight Line Graph $(S L G),(N=364)$

\begin{tabular}{lll}
\hline SLG & Frequency & Percent \\
\hline No Explanation & 177 & 78.3 \\
Not classified & 15 & 6.7 \\
Because when the line passes through all & & \\
the points, it will make the graph to be & & 4.9 \\
overloaded. Hence it passed through only \\
two points, which has made the difference \\
$\begin{array}{l}\text { between the points to be 1 } \\
\text { Because for the graph to be drawn straight, there } \\
\text { must be a correct value plot on the graph }\end{array}$
\end{tabular}

Five physics students were interviewed on data processing items i.e. UR, AN, and SLG. These five physics students were conveniently selected based on how they responded to the UR, AN, and SLG items. The interview was conducted in order to validate the written responses of students.

Researcher: "You wrote $\mathrm{d}=432 \mathrm{~mm}$ under UR; why was $\mathrm{d}=432 \mathrm{~mm}$ the correct answer?"

Student 1: "I wrote $\mathrm{d}=432 \mathrm{~mm}$, this came by adding all the releases of the ball and divided by 5 . The result would give the average distance which then serves as the correct distance of the ball”.

Student 2: "This is because there are variations in the distance. The actual value is obtained by calculating the average distance covered by the ball".

Student 3: could not give any explanation on writing down $\mathrm{d}=432 \mathrm{~mm}$.

The first two students' responses showed clearly that they have internalized the set paradigm concept while student 3 might have gotten the correct answer by guessing, this is because he was not able to explain what he has written i.e. $\mathrm{d}=432 \mathrm{~mm}$.

The following interview questions went to the two physics students who had the item wrong.

Researcher: "Why did you not write $\mathrm{d}=432 \mathrm{~mm}$ under UR item?”

Student 1: "This is because the test has been performed for about five times and each distance is noted".

Student 2: $\quad$ "Because by adding all the results give the answer".

Student 1 response was with the point paradigm concept; this is because he saw each distance as the true value for the distance of the ball. However, student 2 was confused by saying that adding all the results give the answer.

Researcher: "You chose option B under AN; why was this option the correct answer?"

Student 1: "This is because $588 \mathrm{~mm}$ is far away from the rest of the measurement, the rest of the measurement are closer to each other with some small interval within them. Thus $588 \mathrm{~mm}$ should be ignored and the rest of the measurement added and divided by 5 to get the average result".

Student 2: $\quad$ "Because the 4th value is $588 \mathrm{~mm}$. this $588 \mathrm{~mm}$ is not consistent with the rest of the results, so the 4th value should be ignored and then find the average of the rest measured values". 
Kumassah, K. E., Ampiah, J. G., \& Adjei, E.

Student 3: $\quad$ "Because $588 \mathrm{~mm}$ must be ignored then the rest added and divided by 5 . This is because $588 \mathrm{~mm}$ is out of range. This may be due to inaccuracy or error on the scientist part or the instrument used or the experimental conditions such as constant temperature, pressure etc might not have been met".

The three students' responses showed clearly that they have internalized the set paradigm concept. This is because they were able to detect the outlier and also they were able to determine the average of the other results without the use of the outlier.

Researcher: "Why did you not choose option B under AN item?"

Student 1: "Because $588 \mathrm{~mm}$ is a mistake so another measurement must be taken and the average calculated with the 6 values".

Student 2: $\quad$ did not give any response.

Student 1 has internalized the set paradigm concept by detecting that $\mathrm{d}=588 \mathrm{~mm}$ could be due to error in measurement, hence $588 \mathrm{~mm}$ must be ignored and another measurement taken again and average determined. However, comparing student 1 selected option to his oral response showed that this student might have been in a mixed paradigm state. Student 2 might have been confused or he had the answer by mere guessing.

Thus with the Anomaly (AN) item students were of the view that $588 \mathrm{~mm}$ value should be ignored and the rest added and average determined. This response is correct because $588 \mathrm{~mm}$ value is too big a value among the rest of the values; hence it is an outlier that always affects mean results. Thus, when added to the rest of the values and average determine, the average result will not be a representation of the individual results.

The following interview questions went to the physics students who had the item correct.

Researcher: "You drew a two point line graph, such that two points were up the line and three points down the line on SLG item; why was this graph correct?"

Student 1: "The reason for drawing such a graph is that when the line passes through all the points, it will make the graph to be overloaded. Hence it passed through only two points, which has made the difference between the points to be 1 "

Student 2: $\quad$ "Please Sir; I employed the concept of the line of best fit such that the number of points that fell below and above the line is equal or almost equal. This helps in taking the average of the points and hence gives accurate results".

Student 3: "Looking at the nature of the graph, the line will definitely pass through two points by using line of best fit. This makes the graph not to be overloaded since three points were up the line and two points down the line (i.e. $3-2=1$ )"

The three students' responses were completely with the set paradigm concept. This implies that these students have internalized the set paradigm concept; this is because they were able to apply the concept of lines of best fit in order to prevent overloading of the plotted graph.

Researcher: "Why did you not draw a two point line graph, such that two points will be up the line and three points will be down the line under the SLG item?"

Student 1: "This is because the lower points and the upper points were chosen to draw the graph"

Student 2: "Because the graph is a straight line graph"

These two students were confused as to what to write down. 


\section{Key findings}

With students understanding on data processing, all the three items on data processing of students (i.e. UR, AN, and SLG) were in line with the point paradigm concept of measurement. Also students seemed to have difficulty in plotting straight line graph by the use of lines of best fit.

\subsection{Conclusion}

It has been reported by the Physics Chief Examiners' of the West African Exanimation Council that science students made deductions after obtaining only one reading from their experiments. However, the findings of this study showed that science students find difficulty in processing data i.e. using repeat in data set, anomaly in data set and plotting straight line graph. The implication is that students might be able to get the raw data from experiment and even the environment, but they would not be able to process such a data in order to infer and or made judgment from it and made projections for the future. If these problems in students are not attended to now with immediate effect, some of these students will eventually become science teachers of the future and would carry the same problem and conception to the future generation students of the country. In view of the fact that students face difficulty in understanding data processing by the set paradigm concept, science teachers should lay much emphasis on this aspect.

\subsection{Recommendation}

Based on the findings of this study it is recommended that physics teachers should make effort to make scientific measurement by the set paradigm concept relevant to all senior high school science students in Volta Region of Ghana.

\section{Suggestions for Future Research}

$>$ It is suggested that this research can be carried out in other subject areas such as Chemistry, Mathematics and Biology in a wider perspective.

$>$ It is also suggested that this study should be given a nationwide dimension; this will enable policy makers to observe the true picture of science students towards their understanding of scientific measurement in order to obtain and employ professional physics science teachers at the Senior High Schools.

$>$ It is also suggested that any other study on students understanding of scientific measurement should rather be conducted on physics teachers' since some physics teachers could hold onto the point paradigm concept of scientific measurement.

\section{References:}

Allie, S., Buffler, A., Campbell, B., \& Lubben, F. (2001). Point and set paradigms in students' handling of experimental data. Paper in Science Education: Past, Present and Future (pp. 331-336). Dortrecht: Kluwer Academic Publishers.

Allie, S., Buffler, A., Campbell, B., \& Lubben, F. (2003). Teaching scientific measurement at university. The Physics Teacher, 41, 115-117.

Anamuah-Mensah, J., Mensah, F., \& Otuka, J. O. E. (2001). Development of remedial method for teaching electric circuits in secondary schools. African Journal of Educational Studies in Mathematics and Sciences, 1, 31-41.

Ary, D., Jacobs, L. C., \& Razavieh, A. (2002). Introduction to research in education (6 $6^{\text {th }}$ ed.). California: Wadsworth Group.

Azari. N. P., \& Bataille. G. (2003). A theoretical resource for scientific investigation of religious experience. 
Kumassah, K. E., Ampiah, J. G., \& Adjei, E.

\section{JCRT, 4(3), 13-20}

Bassarath, H., \& Whiteley, P. (2009). Measurement and units. Cambridge: Cambridge University Press.

Cardamone. J. M. (2007). Fundamental concept of physics. Florida: Brown walker press.

Deardorff, D. L. (2001). Introductory physics students' treatment of measurement uncertainty. Unpublished doctoral dissertation, North Carolina State University.

Evangelinos, D., Psillos, D., \& Valassiades, O. (2002). An investigation of teaching and learning about measurement data and their treatment in the introductory physics laboratory. In D. Psillos \& H. Niedderer (Eds.), Teaching and Learning in the Science Laboratory (pp. 179-190). Dordrecht: Kluwer Academic Publishers.

Ghana Education Service. (2009). Register of programs for senior high school. Accra: Ghana Education Service Lippmann, F. R. (2003). Students' understanding of measurement and uncertainty in the physics laboratory: social construction, underlying concepts, and quantitative analysis. Unpublished doctoral dissertation, University of Maryland.

Ministry of Education. (2007). Teaching syllabus for physics. Accra: Curriculum Research and Development Division (CRDD).

Sharlow, F. M. (2009). Generalizing the algebra of physical quantities. New York: Mark F. Sharlow Publication.

Sinex, S. A. (2005). Investigating types of errors. Robina: Spreadsheets in Education (eJSiE) of Bond University, 2(1), 1-12

West African Examination Council. (2000). Chiefs Examiner's Report. Accra: WAEC Press.

West African Examination Council. (2002). Chiefs Examiner's Report. Accra: WAEC Press.

West African Examination Council. (2006). Chiefs Examiner's Report. Accra: WAEC Press.

Wilson, B. E. (2009). Physical measurements: An introduction to scientific research. Virginia: Department of Physics, University of Virginia.

Wordsworth. (1998). Wordmaster dictionary. London: Wordsworth Edition Ltd. 


\section{Appendix A}

$$
\text { Instrument }-1 \text { of the study }
$$

A 3 Item Questionnaire on Students' Understanding of Data Processing

Senior High Schools Physics Students' Understanding of Data Processing

SHS Students' form

Part 1: Background Questionnaire

Surname:

First name:

School

Location of School / District:

Type of School $\quad$ [SHS $] \quad$ [SHTS $] \quad$ [BUSINESS $] \quad$ [VOCATIONAL]

Part 2: Laboratory Procedures Questionnaire

Instructions

Write your name in the box above.

Read the text below and answer the questions on each sheet.

If you need more space for your answers, then use the backs of the sheets.

It should take you about 5 minutes to answer each question.

Answer the questions in order and do not skip any sheet.

When you have completed a question, put the sheet inside this envelope and do not take it out again, even if you want to change your answer.

Note: It is possible that some answers may be similar or exactly the same as others. Please write all answers out in full, even if you feel that you are repeating yourself. 


\section{Experimental Context}

An experiment is being performed by students in the Physics Laboratory.

A wooden slope is clamped near the edge of a table. A ball is released from a height $\mathrm{h}$ above the table as shown in the diagram. The ball leaves the slope horizontally and lands on the floor a distance d from the edge of the table. Special paper is placed on the floor on which the ball makes a small mark when it lands.

The students have been asked to investigate how the distance $d$ on the floor changes when the height $h$ is varied. A meter stick is used to measure $d$ and $h$.

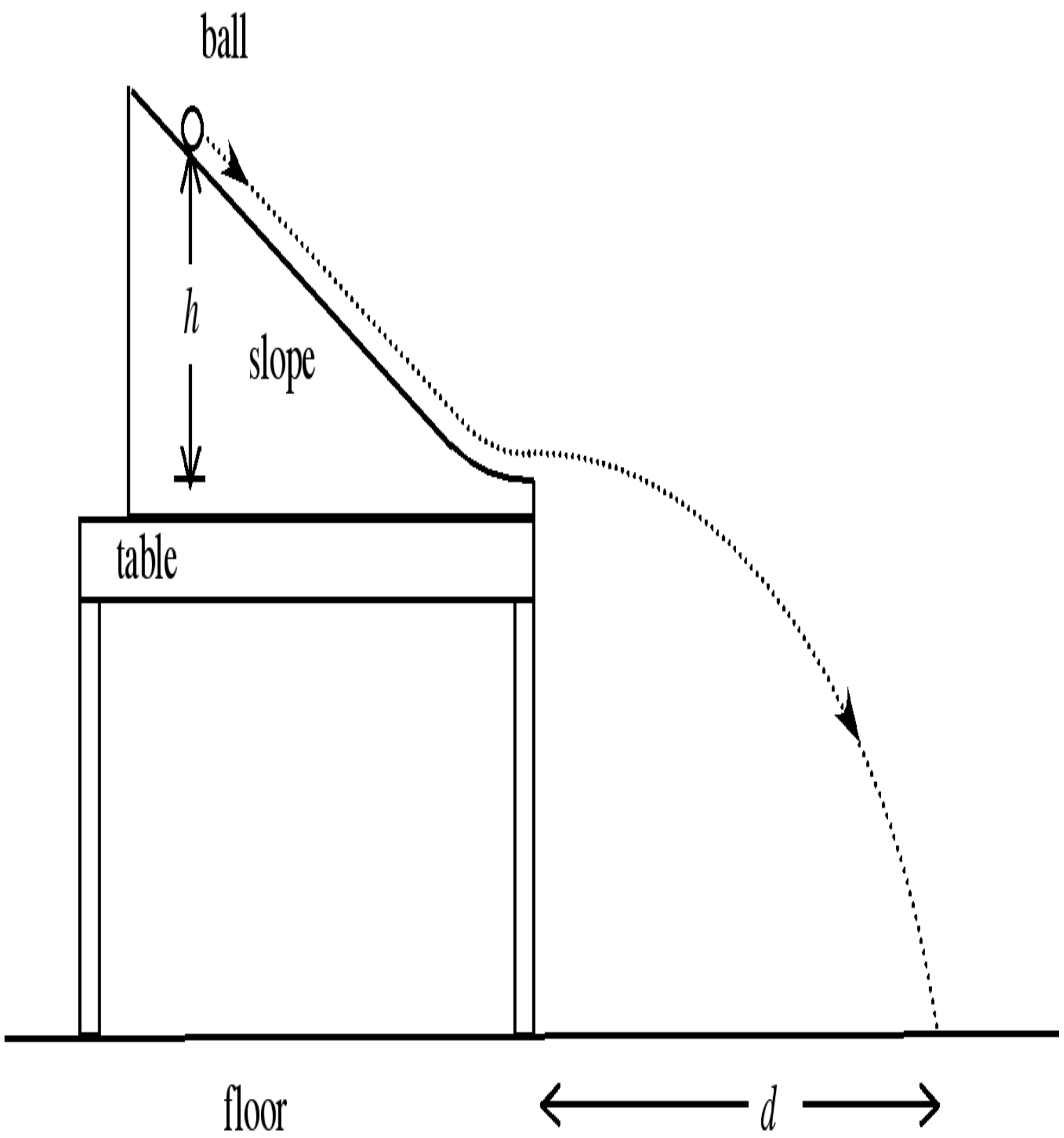


The students continue to release the ball down the slope at a height $\mathrm{h}=400 \mathrm{~mm}$.

Their results after five releases are:

\begin{tabular}{ll}
\hline Release & $\mathrm{d}(\mathrm{mm})$ \\
\hline 1 & 436 \\
2 & 426 \\
3 & 438 \\
4 & 426 \\
5 & 434 \\
\hline
\end{tabular}

The students then discuss what to write down for $\mathrm{d}$ as their final result.

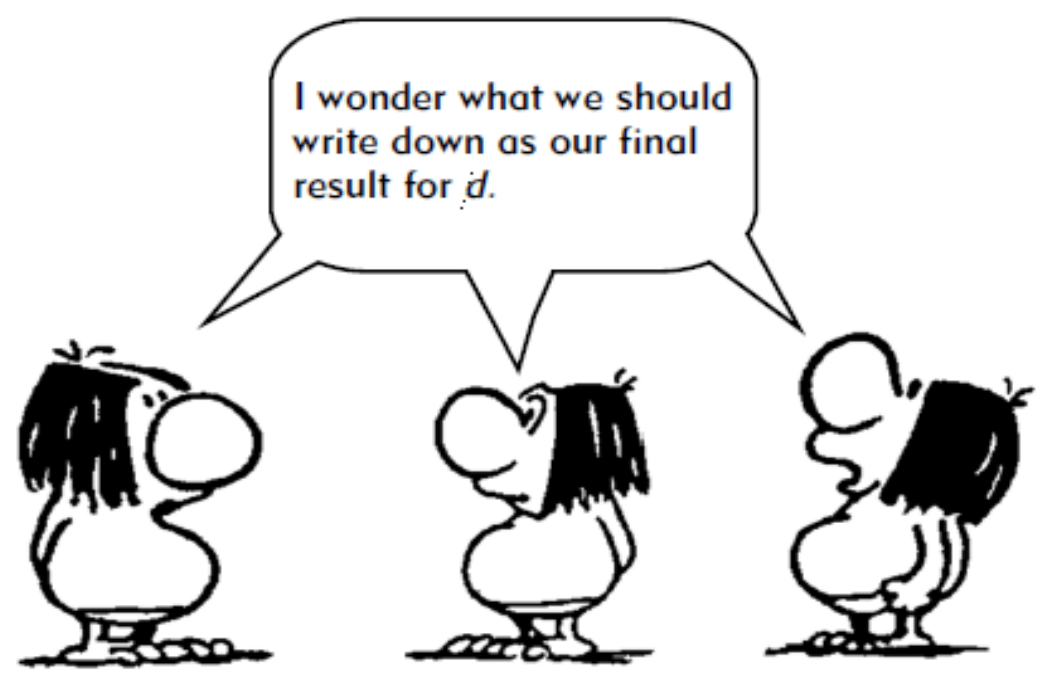

Write down what you think the students should record as their final result for $d$.

Explain your choice. 
Another group of students have decided to calculate the average of all their measurements of $\mathrm{d}$ for $\mathrm{h}=400$ mm.

Their results after six releases are:

\begin{tabular}{ll}
\hline Release & $\mathrm{d}(\mathrm{mm})$ \\
\hline 1 & 443 \\
2 & 422 \\
3 & 436 \\
4 & 588 \\
5 & 437 \\
6 & 429 \\
\hline
\end{tabular}

The students then discuss what to write down for the average of $d$.

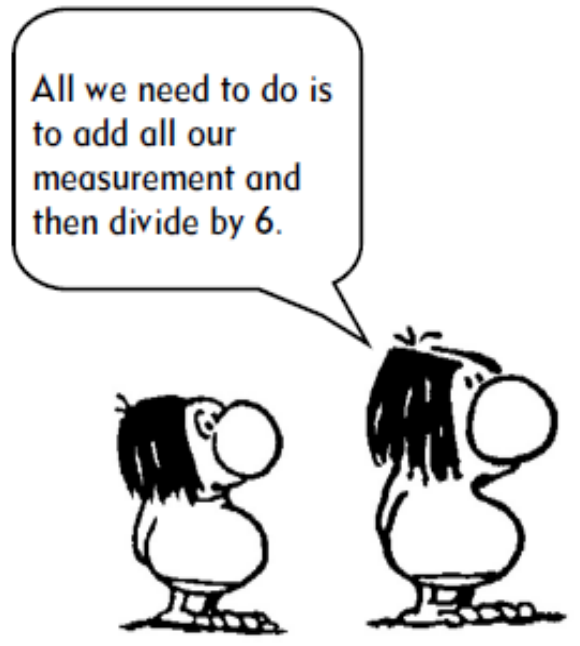

A

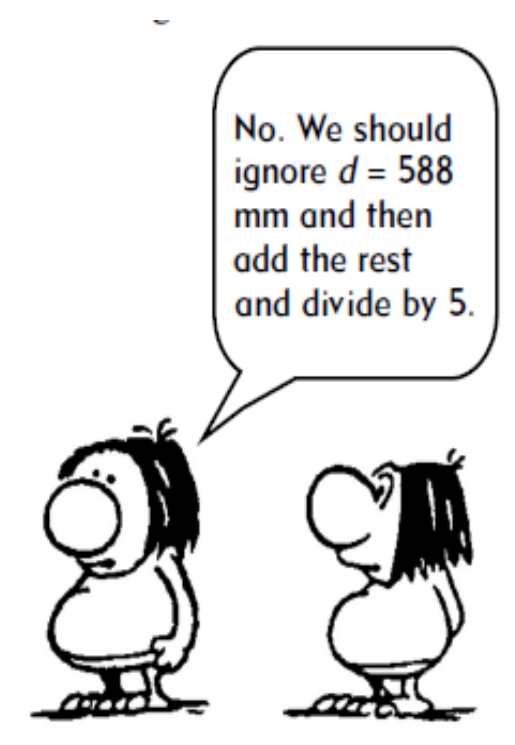

B

With whom do you most closely agree? (Circle ONE):

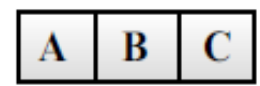

Explain your choice. 


\section{SLG}

A group of students collect data at different heights and use it to plot a straight line graph. The data are plotted below. On this graph, draw the line that you think well fits this data.

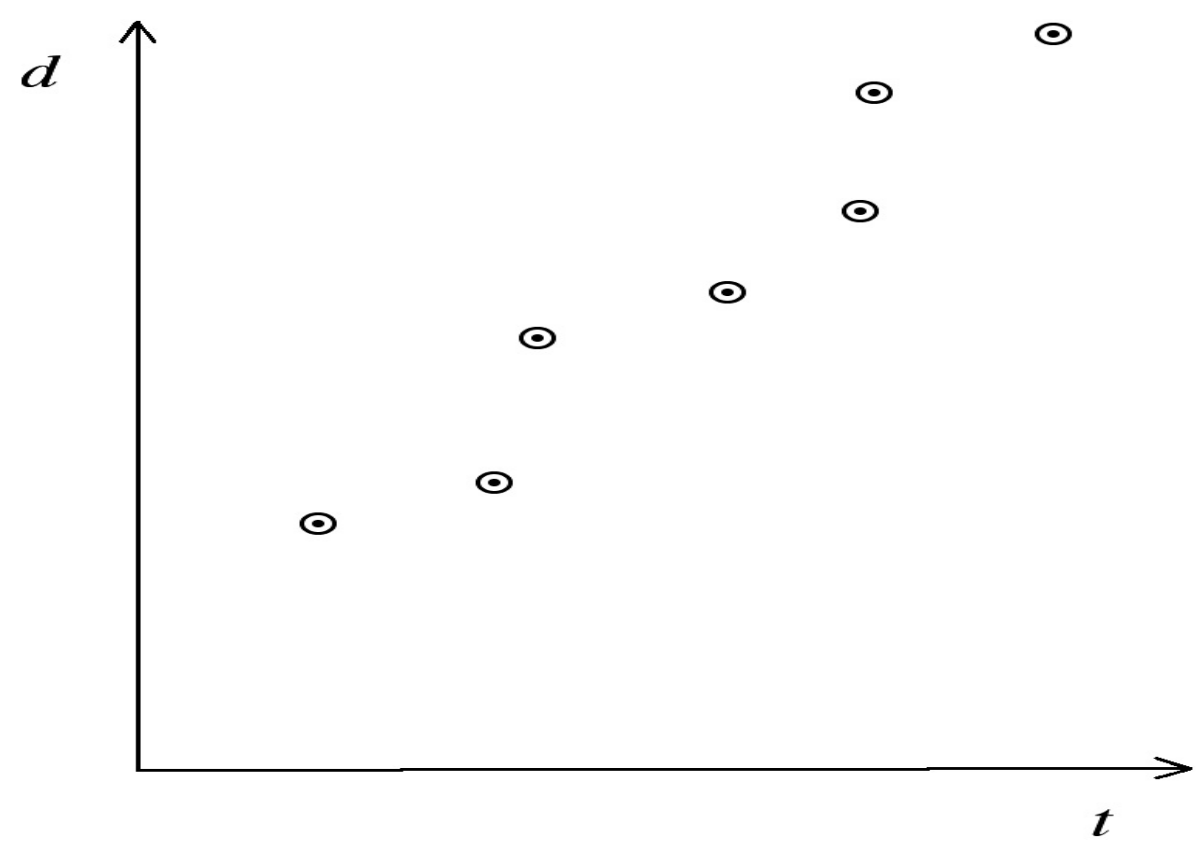

Explain carefully what you have done and why. 


\section{Appendix B}

Instrument-2 of the study

\section{Interview Guide on Students' Understanding of Data Processing}

NB: before the interview, the SHS3 physics students would be made to respond to closed and open-ended questionnaire items which focus on students' reasons for their choice of responses to the questionnaire items.

SHS3 physics students' understanding of data processing of length and time.

The following questions will be asked in respect to student's responses to questions on UR, AN, and SLG.

Question one is for students who got the item correct

1. You chose this response under UR, AN, and SLG; why was this response the correct answer?

Question two is for students who got the item wrong

2. Why did you not write down $432 \mathrm{~mm}$ under UR, choose option B under AN, and draw a graph passing through two points, with two points up the graph, three points down the graph under SLG?. 


\title{
Appendix C
}

\section{Coding Scheme of Students' Responses}

\author{
Using Repeat
}

$\mathrm{UR}_{(432)}$ : I wonder what should write down as our final result for $\mathrm{d}$.

1. Not classified.

2. No explanation given.

3. Because by adding all the releases of the ball and divide by 5 would give the average distance which then serves as the correct distance of the ball.

4. Because the test have been performed for about five times and each distance is noted.

Anomaly

AN (B): No we should ignore $\mathrm{d}=588 \mathrm{~mm}$ and then add the rest and divide by 5 .

1. Not classified.

2. No explanation given.

3. Because $588 \mathrm{~mm}$ is out of range by exceeding all other values, so it should be ignored.

4. Because $588 \mathrm{~mm}$ is far away from the rest of the measurement, while the rest of the measurement are closer to each other with some small interval within them. Thus $588 \mathrm{~mm}$ should be ignored and the rest of the measurement added and divided by 5 to get the average result.

\section{Straight Line Graph}

SLG: On this graph, draw the line that you think best fit this data.

1. Not classified.

2. No explanation given.

3. Because when the line passes through all the points, it will make the graph to be overloaded. Hence it passed through only two points, which has made the difference between the points to be 1 .

4. Because for the graph to be drawn straight, there must be a correct value plot on the graph. 
Kumassah, K. E., Ampiah, J. G., \& Adjei, E. 